\title{
The Effect of Light-Curing Duration and Different Composite Shades on Color Stability of Composite Resins
}

\author{
Nurhanani Mohd Sadek, Nur Syuhadah Jamal, Victor Goh, Goo Chui Ling* \\ Faculty of Dentistry, National University of Malaysia, Jalan Raja Muda Aziz, 50300 Kuala \\ Lumpur, Malaysia \\ *Email: clgoo@ukm.edu.my
}

\begin{abstract}
Aims of this study is to evaluate the effect of light-curing duration using light-emitting diodes (LED) curing units and different composite shades on the color stability of the composite resins. Specimens in four shades of two types of composite resin were prepared and polymerized with the LED curing unit. The initial color parameters $\left(\mathrm{L}^{*}, \mathrm{a}^{*}, \mathrm{~b}^{*}, \mathrm{E}^{*}\right)$ were done using a spectropho-tometer before subjected to a thermocycling regimen comprising of 500 cycles in water of $55^{\circ} \mathrm{C}$ and $5^{\circ} \mathrm{C}$. The final color readout was then performed to determine the color changes using ANOVA and Tukey-Kramer post-hoc test. After thermocycling regimen, the mean delta $E^{*}$ of specimens were in the range of 1.67 to 4.78 . The mean delta $a^{*}$ of specimens were mostly positive, while the mean delta $\mathrm{L}^{*}$ and delta $\mathrm{b}^{*}$ were mostly negative. There was perceptible color change in most of the specimens as they were mostly darker value (negative delta $\mathrm{L}^{*}$ ), shifted towards reddish discoloration (positive delta $\mathrm{a}^{*}$ ) and blueish discoloration (negative delta $\mathrm{b}^{*}$ ). The color change experienced by the specimens could not be anticipated in relation to curing duration and types of composite shades as the effect was more likely dependent on individual material composition rather than actual shade classification. Neither light-cure duration nor difference in shades had significant effect on the amount of color change in composite resins.
\end{abstract}

Keywords: composite resin, color stability, light curing duration, composite shades, light-emitting diodes

\section{Introduction}

The dental light-curing unit (LCU) is an essential part of composite restoration to reach their manufacturer's intended properties and is a basic requirement for predictable long-term clinical success. These composite resins commonly employ camphorquinone as its photoinitiator and an aliphatic amine as an activator which reacts with each other when light-cured to create free radicals and initiate polymerization [1]. However, clinicians often skimp on the duration of their light-curing due to time constraints in a busy clinic. This may possibly result in inadequate photopolymerization of the composite resin. Undercured composite resin present a host of problems such as post-operative sensitivity, marginal breakdown, bulk fracture due to the suboptimal properties and poor clinical performance [2]. 
With increasing emphasis on dental aesthetics, the ability to select the correct shade of composite resin is imperative to produce restorations, which are as imperceptible as possible compared to the natural dentition. Thus, the ability to anticipate the final color characteristics of the composite resin used for restoring teeth is crucial as the human eye is sensitive to changes in the value of the shade, more so in lighter shades [3].

Color stability of the composite resin is dependent on various factors such as the photoinitiator system, resin matrix, light curing variables such as exposure time, light intensity and others [4]. Camphorquinone (CQ) is a photoinitiator component in composite which is yellow in color. It significantly influences the final color of the material although it is used in a small amount as residual CQ, which is not converted during light curing can influence the color of the material. Furthermore, the other important components of photoinitiator system are tertiary amines which can form by-products during photoreaction that tend to cause yellow to red-brown discoloration under the influence of light or heat $[5,7]$. The influence of resin matrix on color stability is also known. Shade shifts towards white and opaque if the matrix is more hydrophilic, but little impact is seen if the matrix is very hydrophobic [67]. Insufficient curing of composite resin and type of light curing units can also affect the color stability of composite resin.

Thus, the aim of this study was to investigate the effect of light-curing duration and different composite shades on color stability of composite resin using light emitting diodes (CURE TC-24 LED) curing units. The null hypothesis tested was the curing duration on different shades of composite resin have no differing effect on color stability of composite resin.

\section{Materials and Methods}

Two brands of composites resin, Filtek Z250xT (3M ESPE) and Ceram.x.one (Dentsply) are selected in shades of A1, A2, A3 and A3.5. Both composites resin contains only camphorquinone as photoinitiator. The light-curing units to be used are a light emitting diode (CURE TC-24 LED) and the curing duration selected are $10 \mathrm{~s}, 20 \mathrm{~s}$ and $40 \mathrm{~s}$. Twenty-four groups of 10 specimens each, totaling to 240 specimens will be prepared.

A 3D printed matrix was used to fabricate $5 \mathrm{~mm}$ in diameter and $2 \mathrm{~mm}$ in thickness specimens according to the group. The composites were inserted into the matrix and compressed with a glass slide to allow excess material to flow out. After insertion into the matrix, the specimens were light activated using the LED lightcuring unit. Subsequently, the test specimens were polished and the thickness was measured with a caliper, since any alterations in test specimen thickness could influence the results.

After obtaining the test specimens, initial color readout was taken using a spectrophotometer (VITA Easyshade) with the specimen placed on a white tile. Next, the samples were subjected to a thermocycling regimen AMMP entre (ATDM T6ED Zactron Sdn. Bhd.) comprising of 500 cycles with dwell time of $60 \mathrm{~s}$ each alternating between water baths with temperatures of $55^{\circ} \mathrm{C}$ and $5^{\circ} \mathrm{C}$. 
After the thermocycling regimen, the final color readout was performed and color stability $(\Delta \mathrm{E})$ was determined by the difference between the coordinates obtained before and after the ageing process of the samples using the formula below:

$\Delta \mathrm{E}=[(\Delta \mathrm{L}) 2+(\Delta \mathrm{a}) 2+(\Delta \mathrm{b}) 2] 1 / 2$

Where the $\Delta \mathrm{E}$ is the color alteration, $\Delta \mathrm{L}=\mathrm{LF}-\mathrm{LI}, \Delta \mathrm{a}=\mathrm{aF}-\mathrm{aI}$ and $\Delta \mathrm{b}=\mathrm{bF}-\mathrm{bI}$.

The subscript letter " $F$ " correspond to the final readout, taken after regimen and "I" to the initial readout. $\Delta \mathrm{L}$ represent the difference in luminosity, $\Delta \mathrm{a}$ the difference in the red green parameter $\left(-\mathrm{a}^{*}=\right.$ green and $\left.+\mathrm{a}^{*}=\mathrm{red}\right)$ and $\Delta \mathrm{b}$ the difference in the yellow-blue parameter $\left(-b^{*}=\right.$ blue and $+b^{*}=$ yellow $)$. Values of $\Delta E$ equal to or higher than 3.3 were considered clinically unacceptable [8-10]. After obtaining the data, the statistical analysis was conducted with SPSS software 16.0 (SPSS Inc. Chicago. IL. USA) using ANOVA, Tukey-Kramer Post Hoc test.

\section{Results}

Table shows the means values and standard deviation for all the color parameters $(\Delta \mathrm{L}, \Delta \mathrm{a}$ and $\Delta \mathrm{b})$ and the color stability $(\Delta \mathrm{E})$ of the specimens after the thermocycling regimen (Table $1 \& 2$ ). $\Delta \mathrm{E} \geqslant 3.3$ which is considered to be clinically unacceptable was found for Ceram.x one with curing time 10s for shade A1 and A2 and 40s for shades A1 and A3. The FiltekZ250xT composites with curing time of 10 s for shade A2, 20s for shade A2 and 3.5 and 40s for shade A3 and A3.5 also showed clinically unacceptable values of $\triangle \mathrm{E}$. However, ANOVA and TukeyKramer post hoc test revealed no statistically significant differences for all groups $(\mathrm{p}>0.05)$.

Table 1. Overall means and standard deviations for $\Delta \mathbf{L}, \Delta \mathbf{a}, \Delta \mathbf{b}$ and $\Delta \mathbf{E}$ of composite resin Ceram $x$. One

\begin{tabular}{|c|c|c|c|c|c|c|c|c|c|c|c|c|}
\hline Compo- & \multicolumn{12}{|c|}{ Ceram $x$ one } \\
\hline Shades & \multicolumn{3}{|c|}{ A1 } & \multicolumn{3}{|c|}{ A2 } & \multicolumn{3}{|c|}{ A3 } & \multicolumn{3}{|c|}{ A3.5 } \\
\hline Times & $10 \mathrm{~s}$ & $20 \mathrm{~s}$ & $40 \mathrm{~s}$ & $10 \mathrm{~s}$ & $20 \mathrm{~s}$ & $40 \mathrm{~s}$ & $10 \mathrm{~s}$ & $20 \mathrm{~s}$ & $40 \mathrm{~s}$ & $10 \mathrm{~s}$ & $20 \mathrm{~s}$ & $40 \mathrm{~s}$ \\
\hline \multirow[t]{2}{*}{$\Delta \mathrm{L}$} & -2.65 & 1.22 & -0.74 & -1.48 & -0.65 & -0.69 & -1.91 & -0.65 & -2.04 & -2.09 & 1.05 & -1.34 \\
\hline & $(2.65)$ & $(1.68)$ & $(2.50)$ & $(1.90)$ & $(0.83)$ & $(1.81)$ & $(1.47)$ & $(0.94)$ & $(1.35)$ & $(1.51)$ & $(2.11)$ & $(1.32)$ \\
\hline \multirow[t]{2}{*}{$\Delta \mathrm{a}$} & 0.32 & 0.40 & 1.12 & 0.46 & 0.25 & 1.41 & 0.45 & 0.32 & 1.69 & 1.09 & 0.58 & 1.62 \\
\hline & $(0.46)$ & $(0.18)$ & $(0.43)$ & $(0.22)$ & $(0.25)$ & $(0.78)$ & $(0.39)$ & $(0.11)$ & $(0.40)$ & $(0.63)$ & $(0.40)$ & $(0.27)$ \\
\hline \multirow[t]{2}{*}{$\Delta \mathrm{b}$} & -1.78 & -1.00 & -2.05 & -1.37 & -0.81 & -1.52 & -3.26 & -1.65 & -1.34 & -2.72 & 0.69 & -1.96 \\
\hline & $(3.22)$ & $(1.73)$ & $(1.60)$ & $(2.21)$ & $(1.20)$ & $(1.57)$ & $(1.47)$ & (1.07) & $(1.69)$ & $(1.51)$ & $(2.85)$ & $(1.27)$ \\
\hline \multirow[t]{2}{*}{$\Delta \mathrm{c}$} & -1.74 & -0.96 & -2.13 & -1.34 & -0.78 & -1.28 & -2.90 & -1.56 & -1.63 & -1.92 & 0.72 & -1.76 \\
\hline & $(3.19)$ & $(1.73)$ & $(1.53)$ & $(2.17)$ & $(1.18)$ & $(1.51)$ & $(1.73)$ & $(1.07)$ & $(1.74)$ & $(2.30)$ & $(2.87)$ & $(1.36)$ \\
\hline \multirow[t]{2}{*}{$\Delta \mathrm{E}$} & 4.78 & 2.43 & 3.31 & 2.85 & 1.67 & 3.03 & 4.08 & 2.01 & 3.28 & 3.93 & 3.20 & 3.16 \\
\hline & $(1.90)$ & $(1.49)$ & $(1.87)$ & $(2.06)$ & $(0.61)$ & $(1.20)$ & $(1.44)$ & $(1.08)$ & $(1.84)$ & $(1.49)$ & $(1.87)$ & $(1.21)$ \\
\hline
\end{tabular}


Table 2. Overall means and standard deviations for $\Delta \mathbf{L}, \Delta \mathbf{a}, \Delta \mathbf{b}$ and $\Delta \mathbf{E}$ of composite resin FiltekZ250Xt

\begin{tabular}{|c|c|c|c|c|c|c|c|c|c|c|c|c|}
\hline Composite & \multicolumn{12}{|c|}{ FiltekZ250Xt } \\
\hline Shades & \multicolumn{3}{|c|}{ A1 } & \multicolumn{3}{|c|}{ A2 } & \multicolumn{3}{|c|}{$\mathrm{A} 3$} & \multicolumn{3}{|c|}{ A3.5 } \\
\hline Times & $10 \mathrm{~s}$ & $20 \mathrm{~s}$ & $40 \mathrm{~s}$ & $10 \mathrm{~s}$ & $20 \mathrm{~s}$ & $40 \mathrm{~s}$ & $10 \mathrm{~s}$ & $20 \mathrm{~s}$ & $40 \mathrm{~s}$ & $10 \mathrm{~s}$ & $20 \mathrm{~s}$ & $40 \mathrm{~s}$ \\
\hline \multirow[t]{2}{*}{$\Delta \mathrm{L}$} & -2.14 & -1.72 & -3.46 & -0.18 & -0.82 & -1.97 & -1.62 & 0.78 & -3.08 & -2.00 & -1.42 & -1.91 \\
\hline & $(2.08)$ & $(2.86)$ & $(2.54)$ & $(1.92)$ & $(2.26)$ & $(1.82)$ & (2.53) & $(1.12)$ & $(2.22)$ & $(1.70)$ & $(2.00)$ & $(1.87)$ \\
\hline \multirow[t]{2}{*}{$\Delta \mathrm{a}$} & 0.83 & 0.53 & 0.62 & 0.46 & 0.54 & 0.36 & 0.27 & 0.29 & 0.80 & 0.92 & 0.90 & 0.89 \\
\hline & $(0.31)$ & $(0.24)$ & $(0.21)$ & $(0.47)$ & $(0.18)$ & $(0.22)$ & $(0.41)$ & $(0.33)$ & $(0.79)$ & $(0.60)$ & $(0.37)$ & $(0.49)$ \\
\hline \multirow[t]{2}{*}{$\Delta \mathrm{b}$} & -1.26 & -0.57 & -2.30 & -0.30 & -0.81 & -0.88 & -1.23 & -0.21 & -2.03 & -3.76 & -1.74 & -2.84 \\
\hline & (1.69) & (2.09) & $(1.91)$ & (2.03) & (2.14) & $(1.75)$ & $(1.86)$ & $(1.48)$ & $(2.55)$ & $(2.25)$ & $(2.15)$ & (2.91) \\
\hline \multirow[t]{2}{*}{$\Delta \mathrm{c}$} & -1.20 & -0.54 & -2.28 & 0.52 & -0.79 & -0.82 & -1.17 & -0.23 & -1.91 & -3.65 & -1.64 & -3.43 \\
\hline & (1.63) & (2.08) & $(1.89)$ & $(1.95)$ & $(2.10)$ & $(1.76)$ & (2.03) & $(1.40)$ & $(2.55)$ & (2.23) & $(2.30)$ & $(1.59)$ \\
\hline \multirow[t]{2}{*}{$\Delta \mathrm{E}$} & 3.09 & 3.33 & 4.28 & 2.26 & 2.62 & 2.91 & 2.98 & 1.92 & 4.41 & 4.49 & 3.07 & 4.63 \\
\hline & $(2.08)$ & $(2.08)$ & $(3.06)$ & (1.64) & (1.98) & $(1.52)$ & $(2.19)$ & $(0.96)$ & $(2.51)$ & $(2.65)$ & $(2.33)$ & $(1.49)$ \\
\hline
\end{tabular}

Most of the $\Delta \mathrm{L}$ (lightness-darkness) value of all groups except for Ceram.x one with curing time 20 s for shade A2 and A3 showed negative mean values, indicating a darker shift of the specimens. Positive mean values of $\Delta \mathrm{a}$ (red-green) and negative mean values of $\Delta b$ (blue-yellow) were observed in all groups relating to the increase in redness and blueness of the specimens. Once again, ANOVA and Tukey-Kramer post hoc test revealed no statistically significant difference for all groups $(p>0.05)$.

\section{Discussion}

Based on the results obtained, the research hypothesis of curing duration on different shade of composite resin have no differing effect on color stability of composite resin could not be rejected. No significant differences were found in color stability for different shades of composites resin, considering the curing times used.

In the present study, only one type of photoinitiator which is camphorquinone (CQ) was evaluated on different shades of composite resin. One type of curing devices, which is LED was also used in this study to cure the composites with different curing times. CQ absorption peak of light is $465 \mathrm{~nm}$ and the LED curing unit supply a blue output near $450 \mathrm{~nm}$ to $470 \mathrm{~nm}$ [11]. Thus it is quite effective in activating the $\mathrm{CQ}$ in the composite resin.

It is interesting to note that the effect of curing duration on the color stability could not be predicted with respect to the shades. The result obtained was varied despite of the curing times and shades of the composites with highest overall changes of color stability: $\Delta \mathrm{E}$ of 4.78 for shade $\mathrm{A} 1$ of ceramX.one with curing time of $10 \mathrm{~s}$. There is no particular shade or curing time that demonstrated obvious changes in color stability.

In all sample groups, the color parameter $\Delta$ a showed positive mean value, which indicates the specimen shifted to reddish discoloration. This was attributed to the 
accelerator or their by-product formed during the initiation process that was thermally attacked by the thermocycling regimen [12].

The color parameter $\Delta \mathrm{b}$ result in negative value indicating the bluish discoloration of the samples for all shades and curing times. The CQ was completely converted by the LED in all three-different curing duration and not compensated by the yellow tinge of by-products from the accelerator. It is predicated that there is no overlapping spectra of LED light and accelerator as the CQ is within the ab-sorption range of LED emission spectrum [12]. A yellow color shift could be seen if overlapping of accelerators occur and overcompensates the blue color shift with its byproducts.

All curing durations used on different shades of composite resin converted the resin matrix appropriately as the color parameter $\Delta \mathrm{L}$ result in negative value (shifted darker) in all samples except for Ceram.x one shade A2 and A3 cured for 20s. The reason for the changes in this specific shades and curing duration are unknown. Increase in lightness due to increasing opacity would indicate an in-crease in water sorption and thus, a change to higher refractive index [7].

In previous study by Brackett MG et.al (2007), the authors found that all shades of hybrid product indicate significant yellowing with use of QTH light but only with one each of microhybrid and microfill [11]. In our present study, only one composite classification, which is the nanohybrid universal composite resin in dif-ferent shades were tested. The variation in color parameters $(\Delta \mathrm{L}, \Delta \mathrm{a}$ and $\Delta \mathrm{b})$ were evaluated, not only the final $\mathrm{L}^{*}, \mathrm{a}^{*}$ and $\mathrm{b}^{*}$ value as performed by Bracket Mg et.al. This allowed us to observe the optical behavior of the composite over the course of time.

According to Silami FD et al. (2003) the CQ yellowing effect on darker shade composite is not as critical as compared to the lighter shades $[8,13]$. Thus, smaller quantities of CQ are added while alternative photoinitiators used may alter the final properties of the material. One limitation of this study is that the exact composition of the tested materials were not exactly known. Different shades of composite resin may have different concentrations of CQ and resin matrix, thus af-fecting the final outcome in the tests.

\section{Conclusion}

Not all materials achieved clinically acceptable results in the tests, with some even showed unacceptable color change values, $\Delta \mathrm{E}>3.3$. No significant differ-ences in color stability were found for different shades of composites resin, con-sidering the curing times used, as it appears to be more dependent on product composition rather than the classification of shades itself.

\section{References}

1. Park J, Ye Q, Topp EM, Misra A, Kieweg SL, Spencer P. Effect of photoinitiator system and water content on dynamic mechanical properties of a light - cured bisGMA/HEMA dental resin. J Biomed Mat Res Part A. 2010 Jun 15;93(4):1245-51.

2. Price RB, Ferracane JL, Shortall AC. Light-curing units: a review of what we need to know. J Dent Res. 2015 Sep;94(9):1179-86.

3. Vandewalle KS, SWIFT J, EDWARD J. Estimated light exposure time for composite resin restorative materials. J Esthet Restor Dent. 2011 Aug 1;23(4):201-4. 
4. Ilie N, Hickel R. Can CQ be completely replaced by alternative initiators in dental adhesives? Dent Mat J. 2008;27(2):221-8.

5. Janda R. Dental materials. In: Pelc H, Elvers B, Hawkins St, Harrer R, Pikart-Mu“ ller M, editors. Synthetic resins. Ullmann's encyclopedia of industrial chemistry, 5th ed. Wein-heim: VCH Publishers; 1987: 277-84

6. Buchalla W, Attin T, Hilgers RD, Hellwig E. The effect of water storage and light exposure on the color and translucency of a hybrid and a microfilled composite. J Prosthet Dent. 2002;87(3):264-70.

7. Rüttermann S, Servos A, Raab WH, Janda R. In vitro effect of light-emitting diode light polymerization on the color stability of three resin-based restorative materials. Acta Odontol Scandinavica. 2008;66(1):43-9.

8. Silami FD, Mundim FM, Garcia LD, Sinhoreti MA, Pires-de FD. Color stability of experimental composites containing different photoinitiators. J Dent. 2013;41:e62-6.

9. $\mathrm{Yu} \mathrm{B}, \mathrm{Lee} \mathrm{YK}$. Influence of color parameters of resin composites on their translucency. Dent Mat. 2008 Sep 1;24(9):1236-42.

10. Ruyter IE, Nilner K, Möller B. Color stability of dental composite resin materials for crown and bridge veneers. Dent Mat. 1987 Oct 1;3(5):246-51.

11. Brackett MG, Brackett WW, Browning WD, Rueggeberg FA. The effect of light curing source on the residual yellowing of resin composites. Oper Dent. 2007 Sep;32(5):44350 .

12. Rüttermann S, Suyoun K, Raab WH, Janda R. Effect of exposure time on the color stability of resin-based restorative materials when polymerized with quartz-tungsten halogen and LED light. Clin Oral Investigations. 2010 Oct 1;14(5):599-605.

13. Alvim HH, Alecio AC, Vasconcellos WA, Furlan M, de Oliveira JE, Saad JR. Analysis of camphorquinone in composite resins as a function of shade. Dent Mat. 2007;23(10):1245-9. 